\title{
Surgical Aspects of No-Touch Saphenous Vein Graft Harvesting in CABG: Clinical and Angiographic Follow-Up at 3 Months
}

\author{
Ninos Samano ${ }^{1,2}$, MD, PhD; Bruno Botelho Pinheiro ${ }^{3}$, MD, MSc; Domingos Souza' ${ }^{1}$ MD, PhD
}

果

DOI: $10.21470 / 1678-9741-2018-0352$

\begin{abstract}
With more than 800,000 coronary artery bypass grafting (CABG) operations annually worldwide and the saphenous vein being the most common conduit used, there is no question that improving saphenous vein graft patency is one of the most important tasks in CABG. This video describes the no-touch harvesting procedure of the saphenous vein on an 80-year old man with hypertension, hyperlipidemia and a previous myocardial infarction with percutaneous coronary intervention to the right coronary artery. He was complaining of exertional chest pain and was diagnosed with stable angina pectoris. The coronary angiography showed advanced three vessel disease with significant stenoses in the left anterior descending (LAD) artery, two marginal arteries (MAs) and the posterior descending artery (PDA), in addition to an occluded
\end{abstract}

diagonal artery (DA). The patient received a triple sequential notouch vein graft to the PDA and two MAs together with a double sequential no-touch vein graft to the DA and LAD. A vein graft was used to bypass the LAD due to the age of the patient and the low degree of stenosis in the LAD. The no-touch harvesting technique is described in detail in the film with complete narration. A follow-up of this patient was performed at three months both clinically and with a computed tomography angiography (CTA). No angina pectoris symptoms were reported by the patient and the wounds in the chest and lower limb were completely healed. The CTA showed patent no-touch saphenous vein grafts to all the distal anastomoses.

Keywords: Coronary Artery Bypass. Saphenous Vein. Vascular Patency. Mammary Arteries.

\begin{tabular}{ll} 
Abbreviations, acronyms \& symbols \\
\hline CABG & $=$ Coronary artery bypass grafting \\
CTA & $=$ Computed tomography angiography \\
DA & $=$ Diagonal artery \\
LAD & $=$ Left anterior descending \\
MAs & $=$ Marginal arteries \\
PDA & $=$ Posterior descending artery
\end{tabular}

\section{PATIENT CHARACTERISTICS}

Eighty-year-old man with hypertension, hyperlipidemia and a previous myocardial infarction with percutaneous coronary intervention to the right coronary artery. The ejection fraction was $55 \%$ and he was complaining of exertional chest pain. The coronary angiography showed advanced three-vessel disease with significant stenoses in the left anterior descending (LAD)

'Department of Cardiothoracic and Vascular Surgery, Faculty of Medicine and Health, Örebro University, Örebro, Sweden.

${ }^{2}$ University Health Care Research Center, Faculty of Medicine and Health, Örebro University, Örebro, Sweden.

${ }^{3}$ Department Cardiovascular Surgery, Hospital do Coração Anis Rassi, Goiânia, GO, Brazil.

The study was carried out at the Department of Cardiothoracic and Vascular Surgery, Faculty of Medicine and Health, Örebro University, Örebro, Sweden.

No financial support

No conflict of interest. artery, two marginal arteries (MAs) and the posterior descending artery (PDA), in addition to an occluded diagonal artery (DA). The patient received a triple sequential no-touch vein graft to the PDA and two MAs together with a double sequential no-touch vein graft to the DA and LAD. A vein graft was used to bypass the LAD due to the age of the patient and the low degree (60-70\%) of stenosis in the LAD.

\section{SURGICAL TECHNIQUE}

The no-touch technique in harvesting the saphenous vein consists of several steps in order to get a good quality conduit as well as to reduce leg wound complications (Video 1). Previous studies have shown a superior patency for the no-touch vein grafts in both the short- and long-term ${ }^{[1-4]}$.

\section{Vein Mapping}

Preoperative vein mapping facilitates rapid and accurate location of the vein, thus reducing soft tissue injury and the

Correspondence Address:

Domingos Souza

iD https://orcid.org/0000-0002-2186-6642

Faculty of Medicine and Health, Örebro University

Cardiothoracic and Vascular Surgery

Södra Grev Rosengatan Örebro 70382, Sweden

E-mail: domingos.ramos-de-souza@regionorebrolan.se

Article received on October 31 st, 2018. Article accepted on October 31 st, 2018. Fast Track 
Video 1 - Surgical technique of no-touch saphenous vein graft harvesting in coronary artery bypass grafting.

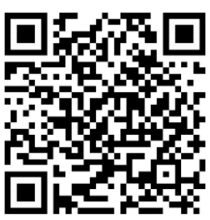

creation of tissue flaps. It also helps to predetermine the best segment of the vein for grafting.

\section{Exposure}

An incision is made through the skin and the saphenous vein is exposed by lifting the edges of the skin. This enables the identification of the correct dissection plane. The diathermy knife can consequently be used safely. The subdermal vessels are ligated to avoid overuse of diathermy.

\section{Marking of Pedicle}

The pedicle is marked with a diathermy knife approximately $0.5 \mathrm{~cm}$ from the both sides of the vein. The large vasa vasorum and the small side branches are ligated proximally with clips. On the other hand, larger side branches should be ligated with a suture.

\section{Removal from Bed}

The saphenous vein is removed from its bed using both scissors and a diathermy knife. The same dissection plane is maintained along the whole length of the graft (Figure 1). After removal, the vein is stored in heparinized blood.

\section{Closure of the Wound}

The wound should be closed in two to three layers. The first layer is especially important to avoid the creation of a dead space where the fascia is usually included in the suture. The second layer is to bring the edges together without tension in the skin. The third layer is with a continuous intracutaneous suture. We recommend performing two separate incisions excluding the knee area as this is more convenient for the patient.

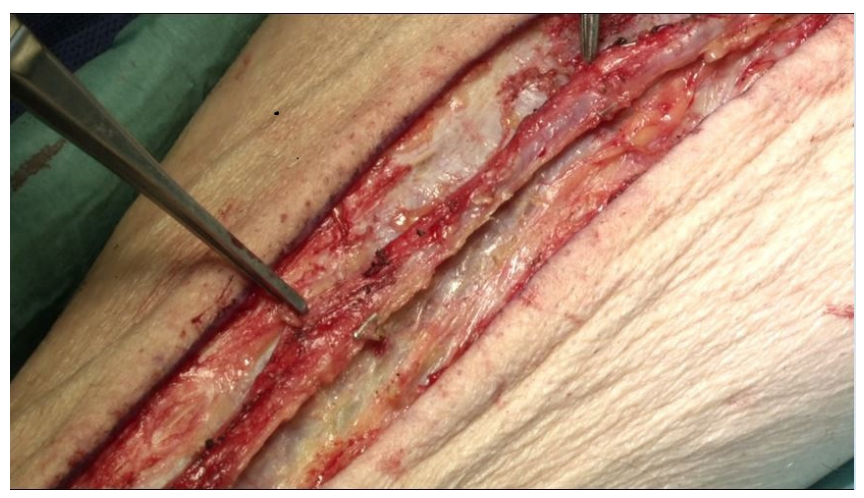

Fig. 1 - No-touch vein graft in situ.

\section{Checking for Leakage}

After starting cardiopulmonary bypass and before cross clamping the aorta, the vein graft is connected to the arterial line and any unligated side branches can be identified. The end of the graft is then prepared for the distal anastomoses. This can be achieved in off-pump surgery by performing the proximal anastomsis first. Only one side of the vein is dissected. This allows a simple grasping of the pedicle without direct manipulation of the vein.

\section{Distal Anastomosis}

The perivascular tissue is used to grasp the vein, giving a good exposure during the suturing. After each complete distal anastomosis, the vein is briefly connected to the arterial line to check for leakage. Finally, the pedicle is fixed to the epicardium at the level of the anastomosis. The no-touch vein simplifies the use of sequential grafts as kinking is not an issue.

\section{Central Anastomosis}

After release of the cross-clamp, the grafts are now connected to the arterial line to allow early myocardial perfusion. This also helps to determine graft length, recheck for bleeding and to maintain relaxation of the vein. The central anastomoses are performed in a classic fashion. A final inspection of the grafts before weaning off cardiopulmonary bypass is also recommended.

\section{Flow Measurement}

Flow measurement with a transonic coronary flow probe is always performed after weaning off cardiopulmonary bypass.

\section{Authors' roles \& responsibilities}

NS Substantial contributions to the conception or design of the work; or the acquisition; drafting the work or revising it critically for important intellectual content; final approval of the version to be published

BBP Substantial contributions to the conception or design of the work; or the acquisition; drafting the work or revising it critically for important intellectual content; final approval of the version to be published

DS

Substantial contributions to the conception or design of the work; or the acquisition; drafting the work or revising it critically for important intellectual content; final approval of the version to be published

\section{REFERENCES}

1. Souza DS, Dashwood MR, Tsui JC, Filbey D, Bodin L, Johansson B, et al. Improved patency in vein grafts harvested with surrounding tissue: results of a randomized study using three harvesting techniques. Ann Thorac Surg. 2002;73(4):1189-95.

2. Souza DS, Johansson B, Bojo L, Karlsson R, Geijer H, Filbey D, et al. 
Harvesting the saphenous vein with surrounding tissue for CABG provides long-term graft patency comparable to the left internal thoracic artery: results of a randomized longitudinal trial. J Thorac Cardiovasc Surg. 2006;132(2):373-8.

3. Samano N, Geijer H, Liden M, Fremes S, Bodin L, Souza D. The no-touch saphenous vein for coronary artery bypass grafting maintains a patency, after 16 years, comparable to the left internal thoracic artery: a randomized trial. J Thorac Cardiovasc Surg. 2015;150(4):880-8.

4. Samano N, Geijer H, Bodin L, Arbeus M, Mannion JD, Dashwood M, et al. The no-touch saphenous vein graft in elderly coronary bypass patients with multiple comorbidities is a promising conduit to substitute the left internal thoracic artery. J Thorac Cardiovasc Surg. 2017;154(2):457-66. 